\title{
Weight Training for Speed and its Impact on the Skillful Performance of Basketball Players
}

\author{
Bouzakaria Touhami, Sekarna Djamel Ali, Amrouche Mustapha and Labane Karim* \\ Institute of Physical Education and Sports, University of Algiers 3, Algeria
}

Submission: August 29, 2018; Published: September 10, 2018

*Corresponding author: Labane Karim, Institute of Physical Education and Sports, University of Algiers 3, Algeria, Tel: 2130666607816;

Email: labakarim@yahoo.fr

\section{Abstract}

The purpose of the study is to know the effect of the weight training method on the performance of skilled basketball players, while specifying and highlighting the contribution of weight training to the development of the technical side, especially the strength of implementation and speed of completion. The study sample was divided into two teams that were active at the same level, the study sample was chosen in a deliberate manner. This was done after the exploratory study, among the teams were Widad Boufarik and the Union of the Capital, but the conditions were more By the team of the Union of the capital, which we received great facilities from the coaches, as well as the great response that we found by the players, as well as the appropriate conditions for observation in the hall of the team of the Capital Union, the team was chosen as well as 3 teams of the same championship, namely MO Ouargla, Sports Association of Hamma EL- Anasar, the sports association of Khemis Meliana, to observe the matches that will bring these teams with the team Union Capital.

Finally, it is possible to say that the results obtained were mostly statistical in terms of the use of weight training method, which came in equal terms in terms of strength and speed. These results have an effect on the performance side of basketball players in positions of pregnancy or without carrying the ball.

Keywords: Weight training; Strength; Speed; Skill performance; Characteristics of basketball players

\section{Introduction and Problem}

Sports activities, such as basketball, rely on basic skills as an important base for progress so that athletes and trainers spend most of their time teaching and training to perform and teach these skills and give them a greater share in educational and training programs [1]. But long time in physical training is not the only way to learn motor skills Basic There are many ways and methods that help to quickly learn and acquire motor skills [2].

The basic skills are essential factors for the success of the player and therefore the team. Therefore, the ability to master them depends directly on the player's desire and his conviction in the regular training and goal of each team or individual basic principles and skills by which access to master the game well and the higher the performance of skills and basic principles overall performance. In basketball, as Faiz Hammoudat et al. refers to basic skills and principles, they mean a set of systems and methods for moving and moving with a ball and without a ball also means the performance of the technique and tactics [3].

It is not only the performance of these skills that perform sound mechanics, but also the way these principles and skills are used in the play situations and conditions and their application against various opponents. The basic skills are those skills that must be mastered by all players in any team, but the special skills are skills that are uniquely applied by a group of players either because of their playing conditions or their superiority in the overall performance of the game, as well as their general skills [4]. On the other hand, we see that the skill side is largely related to the physical aspect of the athlete, and this integration is proportional to the elements of physical characteristics. In our study, it can be said that force is of great importance in performance, because the movement always leads against resistance and especially with athletes who perform their movements (Power x speed) and by increasing the power component increases the output of power, which is an important element in many motor performances and strength is also a key and important factor in the endurance component. They are the ability of the muscles to resist B during the performance of physical exertion.

In this regard, the researcher believes that strength is important in sports performance, it is an important factor to protect the athlete from injuries, strong muscles enable the athlete to move quickly and avoid collisions and injury and increases the stability of joints. Speed is a genetic trait, but modern sports training plays an important role in improving performance and taking advantage of this genetic status to the 
highest degree possible. In the absence of this trait it is very difficult to develop a player's speed to above the intermediate level [4]. In basketball, the speed of the player is shown in his ability to start fast and the ability to gain the maximum speed during the first five meters, and the characteristics of the player fast ability to run fast short or medium distances ranging from (5-50) meters or without ball with the ability to change the speed of speed During jogging in a fluid manner and the ability to change direction during quick jogging whether or not holding the ball.

And through all the above mentioned and because of the importance of this subject, especially that this stage of preparation, which gives the real picture and perception of the level of players before the competition, and used the researcher experimental method to suit for such topics, the main question was asked: How affect exercises weight specific by force and speed on the skillful performance of basketball players? We can proceed by asking partial questions as follows:

a) How do drills affect the weight of strength and speed on the offensive skill of basketball players?

b) How do exercises impact the weight of the distinctive strength and speed on the skillful defense of basketball players?

\section{Hypotheses}

\section{General}

Weight training with strength and speed positively affects the skillful performance of basketball players.

\section{Partial}

Strength and speed training exercises have a positive impact on the athletic performance of basketball players. Exercises with weights marked by strength and speed affect positively on the skillful defense performance of basketball players.

\section{Research Objectives}

The subject of the research that we are dealing with and in order to determine its scientific nature, we decided to set some of the goals that we would like to achieve according to the following points:

a) Access to illustrate the impact and importance of muscle preparation in athletes in general and basketball players in particular.

b) To highlight the role of determining the technical skills of the basketball players during the interviews, whether defensive or offensive.

c) Identify and highlight the importance basketball coaches attach to the use of direct weight training and their reflection in identifying all technical skills that appear during interviews.

\section{Terminology}

\section{Weight Training}

Weight training is a term used to describe one type of exercise that requires moving the muscles of the body or trying to move against some forms of resistance, which are different types of free weights and weights [3]. Many scientists report that the aim of the weight training program is to increase muscle strength, protect muscles, balance muscle groups, increase muscle contraction and prevent injuries. Weight training also helps to improve the efficiency of internal organs (heart-respiratory) and improve technical performance.

\section{Muscle Strength}

Ozoualin says force directly affects speed, performance, skin, and skill. Barou et Mack says that muscle strength is one of the dynamic factors of motor performance and is the cause of progress in this performance, where it stops resistance and the continuity of the progressive program. Djiti L, conducted a study on students who were dismissed due to poor achievement and found that $83 \%$ of them were retarded by muscular strength. Mack and Kwifild studied at Orgone University and found that the weakest demand for fitness was their low level of achievement [3].

\section{Skill}

It is all that can be expressed by achievement, which indicates what the individual learned and the level of his proficiency of what he learned [1]. "And skill" as the character of the movement if repeated one track and one time and a certain direction and a certain force and have a beginning and an end, so the volleyball mockery with offensive skills and defense skills and agrees. The basic skills in Basketball are the movements that the player should perform according to the conditions required by the volleyball game in order to achieve good results, but Balli $\mathrm{L}$ and Tiller F point out that skill is the effective means the team uses in game plans to achieve its goal of winning the game [4].

\section{Somatotype Variables}

Somatotyping is a method of description and assessment of the body on three shape and composition scales: endomorphy (relative fatness), mesomorphy (relative musculoskeletal robustness), and ectomorphy (relative linearity) [5].

\section{Antropometric Parameters}

The physical specifications (anthropometric) as the basis for the fundamental pillars that must be provided to access the individual athlete to the highest possible level, and on the other hand, the structural composition of the body plays a big role and a key to athletic performance, and begin importance of anthropometric measurements in that they are often used as a basis the success or failure of the specified activity, and this is confirmed by both the chlorine and other 1997 studies, Bouchard and others. 


\section{Comment on Similar Studies}

We have noticed the absence of some studies dealing with the training of heavy weights, so that there are those who touched on the study:

a) The skillful side neglecting the method of training this aspect, despite the reference of some studies of the repetition technique [2].

b) Talk about the offensive plans of basketball players to mention the skills that must be developed by training the classes of strength and speed, especially in the areas of the rival, to conduct the skills of payment and enter the defense area [6]

c) Not to address the training of muscle training which is essential for the development of strength and speed in the development of the skillful performance of basketball players [7].

\section{Methodological Framework}

\section{Method Used in the Research}

The researcher used the experimental method, because it is one of the earliest approaches to the correct scientific method and certainty in the search for truth and discovery, interpretation, prediction and control.

\section{The Research Community}

Each group is intended for the statistical units for which we want to collect information. In this study our society may represent the Algerian basketball teams, which are active in the first national division (A and B) where there are 28 teams, A, and 12 team at level $b$.

\section{The Study Sample was Chosen in a Deliberate Manner}

This was done after the survey. We found great cooperation by gestion officers, Widad Boufarik and the Union of the Capital. However, the conditions were more prepared by the team of the Union of the capital, which we received great facilities from the coaches, As well as the great response we found from the players. As well as the appropriate conditions for observation in the hall of the team of the capital, the team was chosen as well as 3 teams of the same tournament and to observe the matches that will bring these teams with the team of the Union of the capital. These teams were as follows:
a) Mouloudia Olympique Ouargla (MOO)
b) Hamma El- Anaser Sports Association (ASHA)
c) Meliana Sports Association (ASM)

\section{The Tools and Techniques Used in the Research}

Experimental studies require devices and laboratories multiequipment for various disciplines and tests as well as programs to measure the variables and the absence of these devices the researcher used special devices, namely: a) Packard Bell laptop computer.

b) The Lunch Mbt Smart Stat program, which is applicable to international events, the International Basketball Federation, and the continental events.

This program was obtained through the management of the Wadad Bufarik team. This program gives different team data through all the skills used during the game.

\section{Authenticity of the tool}

The truthfulness of the means of research we used is subject to several stages of certain methods in our search, we sought the authenticity of the virtual search tool. The latter has been used in several studies, whether international, Arab or some local studies. We have provided this tool to some of the lecturer's arbitrators at the Institute of Physical Education and Sports as well as some professors at the National Institute of Science Technology Sports.

\section{Stability}

The stability of the test of the methodological stages undertaken by the researcher to give the scientific significance. We calculated a correlation coefficient for Spearman Brown. We found that there was a very large correlation after the first application and the second (the method of application and its return), it was estimated: $t=0.82$. The search tool used has high stability.

\section{Statistical Methods Used}

For accurate results were used the most appropriate statistical means: Percentage, Arithmetical mean, standard deviation, variance analysis index, and test for the difference of T- Student.

\section{Results and Analyzed}

Table 1: Shows the significance of the differences between the results of the tribal and remote tests of the two types of research (control and experimental).

\begin{tabular}{|c|c|c|}
\hline & T- Calculate & T- Tabulate \\
\hline $\begin{array}{c}\text { The most basic offensive } \\
\text { techniques }\end{array}$ & 1.68 & 1.41 \\
\hline Number & 16 & 16 \\
\hline Participation & $98 \%$ & $78 \%$ \\
\hline Offensive (rebounds) & 1.62 & 1.41 \\
\hline Number & 16 & 16 \\
\hline Critical moves in the attack & 1.61 & 1.41 \\
\hline Number & 16 & 16 \\
\hline Signification & $* * *$ & $* *$ \\
\hline
\end{tabular}

${ }^{*}$ During interviews in offensive situations.

By asking the research question, the researcher conducted the statistical treatments as follows: We will show through this study three courses showing the effect of weight training distinctive strength and speed on the skill performance of 
basketball players, with the possibility of significant differences, in terms of what is mentioned in the variables of hypotheses mentioned nose.

By noting Table 1, we can say that the comparisons we derive from observation and analysis of interviews between UEFA rivals, we can say that there are statistically significant differences between the tribal and the post-test in the offensive cases of the club of the Capital Union as follows:

a) In Terms of Offensive Base Techniques: Calculated 1.68 greater than the scale of 1.41 at the significance level 0.05 and the degree of freedom 12 , then there is a significant difference to the validity of the post-test after the exercise weight for strength and speed.

b) In Terms of Offensive Rebounds: Calculated 1.62 greater than the scale of 1.41 at the significance level 0.05 and the degree of freedom 12, then there is a significant difference to the validity of the post-test after the exercises with weights for strength and speed.

c) In Terms of Critical Passes in the Attack: Calculated 1.61 greater than the scale of 1.41 at the level of significance 0.05 and the degree of freedom 12 , there is therefore a significant difference to the validity of the post-test after the exercise weights for strength and speed.

Table 2: Shows the significance of the differences between the results of the tribal and remote tests of the two research samples (control and experimental).

\begin{tabular}{|c|c|c|}
\hline & T- Calculate & T- Tabulate \\
\hline The most basic defensive techniques & 1.57 & 1.41 \\
\hline Number & 16 & 16 \\
\hline Participation & $98 \%$ & $92 \%$ \\
\hline Defenders (defensive) & 1.45 & 1.41 \\
\hline Number & 16 & 16 \\
\hline Defense man for man & 1.66 & 1.41 \\
\hline Number & 16 & 16 \\
\hline Signification & $* * *$ & $*$ \\
\hline
\end{tabular}

*During interviews in defense cases.

By asking the research question, the researchers conducted the statistical treatments as follows (Table 2): It is possible to say that there are statistically significant differences between the tribal and the remote tests in defensive cases of the Union of Capital Club as follows:

a) In Terms of Basal Basal Techniques: calculated at 1.57 times greater than the scale of 1.41 at significance level 0.05 and the degree of freedom 12, then there is a significant difference in the validity of the post-test after weight training for strength and speed.

b) In Terms of Defensive Rebounds: 1.45 times greater than the scale of 1.41 at the significance level of 0.05 and the degree of freedom 12 , then there is a significant difference in the validity of the post-test after the exercise with weights for strength and speed.

c) In Terms of Defense Man for Man: where calculated 1.66 greater than the scale of 1.41 at the level of significance 0.05 and the degree of freedom 12, then there is a significant difference to the validity of the post-test after the exercise weights for strength and speed.

Table 3: Represents frequencies and percentages, and the values of k 2 phrases second axis (Coach's Opinion's).

\begin{tabular}{|c|c|c|}
\hline & $\begin{array}{c}\text { Before the } \\
\text { COMPETITION }\end{array}$ & $\begin{array}{c}\text { After the } \\
\text { COMPETITION }\end{array}$ \\
\hline Defense & Yes:79\% No: $21 \%$ & Yes: $88 \%$ No: $12 \%$ \\
\hline Nbre & 16 & 16 \\
\hline Participation & $96 \%$ & $90 \%$ \\
\hline Offensive & Yes:89\% No: $11 \%$ & Yes: $71 \%$ No: $19 \%$ \\
\hline Age & $19.17 \pm 0.89$ & $19.17 \pm 0.89$ \\
\hline Other's Situations & $0.88 \pm 0.50$ & $0.97 \pm 1.01$ \\
\hline the average & $* * *$ & $*$ \\
\hline Participation & $17.16 \pm 089$ & $19.08 \pm 1.45$ \\
\hline
\end{tabular}

By asking the research question, the researchers conducted the statistical treatments as follows (Table 3): We also note in this table that the views of trainers in terms of the impact of weight training on the skill side in the defensive and offensive situation and other situations, and this during and after the competitions, it can be said that:

a) There is $79 \%$ of the players perform purely skilled, compared to $21 \%$ of them are unacceptable in terms of plans in defense positions.

b) There is $89 \%$ of the players perform purely skilled, compared to $11 \%$ of them are unacceptable in terms of plans in offensive positions.

c) Minor differences of $0.88 \pm 0.50$. The players performed purely skill, compared to $0.97 \pm 1.01$, which is unacceptable in terms of plans in other modes.

\section{Discussion}

Discussion of the results of the research in light of the first hypothesis: With regard to the text of the first hypothesis, which is that the effect of the use of weight training on muscle strength on the elements of the performance of offensive skills of basketball players during interviews. By observing and analyzing the results of Table 1 of the sample interviews (DC team), we found a difference in the skill performance elements of the players in an attack mode, which can be mentioned as follows:

a) We have observed that there is a difference between the sample of interviews with the development of this type of skill performance and the increase of a significant number, as we agree [8]. 
b) The critical passes, this type is the cornerstone of the end of the offensive work of the players, where we have seen significant progress in terms of increasing the number of passes, the more frequent the course of interviews as the performance of attacks increased the team, according to Bruno E [1].

It can be said that training using weights gives a positive effect to the development of the ratio of the elements of skill performance [3]. Discussion of the results of the research in the light of the second partial hypothesis: The second premise is that the use of weight training for muscle strength is influenced by the defensive performance of basketball players during interviews. By observing and analyzing the results of Table 2 of the sample interviews (DC team), we found a difference in the skill performance elements of the players and this in an attack mode, which can be mentioned as follows:

a) Defenders: Repeated and repeated, this is due to the fitness of its component, especially speed and strength and sometimes in the apostates use the players of the complex qualities [4], which determines to overcome the attackers with the power of speed to seize the ball and build offensive plans or surprise the opponent, and this as we agree.

b) Defense Man to Man: This is as shown in the second table, which gave the results of the function, in terms of differences in the response to the performance of the attackers in terms of the use of force and speed to remove and reduce the offensive skills of the competitor, as the researchers pointed out in their study of the importance of training muscle strength in defense performance For players [1].

\section{Conclusion}

It is possible to say that the method of weight training characterized by strength and speed, positively affect the performance of skilled basketball players, in terms of the defensive and offensive positions of the team. In our research, it is necessary to work on the development of the elements of physical fitness of basketball players by training the muscle side to identify some of the physical qualities necessary and appropriate for the development of the skill to give a distinctive performance, which depends on the strength and speed of implementation in both Defensive or offensive situations.

Therefore, it is necessary for the trainers to take part of the physical preparation of weight training to develop the muscular system of the athlete, with the development of certain physical attributes such as strength and speed [9] and often compound physical or compensatory qualities such as the force characteristic of speed, explosive force, or compensation factor, Especially the development of muscles to perform certain skills. Finally, we can talk about the preparation of players in terms of control and accuracy of skill performance, which is closely linked to the muscular side of the athlete, using the physical qualities required in the achievement of skill and motor.

\section{References}

1. Bruno E (2006) Observer et évaluer l'apprentissage. CONBB, Paris, p. 29.

2. Clark M (2006) Optimum performance training: Basketball. Regan Boocks, USA, p. 63.

3. Malfois C (2009) Basket- Entrainment des jeunes. mphora, Paris, p. 39.

4. Vincent P (2013) Basket- La Formation des joueurs. Chiron, Paris, p. 79.

5. Heath C (2008) Somatotyping: Development and Applications. Broché, Cambridge University Press.

6. Kuhn F (2018) Prépa Physique Basket. Amazon, Paris.

7. Vincenzi JP, Blonde A (1996) Basketball: Jeux d'entrainement. Chiron, Paris, p. 31.

8. Huguet S (2014) Sport - Psychologie et performance - Du sportif au champion: La quête de soi. mphora, paris.

9. Yessis M (2003) Explosive Basketball Training. Roché, USA.

\section{Your next submission with Juniper Publishers will reach you the below assets}

- Quality Editorial service

- Swift Peer Review

- Reprints availability

- E-prints Service

- Manuscript Podcast for convenient understanding

- Global attainment for your research

- Manuscript accessibility in different formats

( Pdf, E-pub, Full Text, Audio)

- Unceasing customer service

Track the below URL for one-step submission https://juniperpublishers.com/online-submission.php 